\title{
Letter by Hope et al Regarding Article, "Bicuspid Aortic Cusp Fusion Morphology Alters Aortic Three-Dimensional Outflow Patterns, Wall Shear Stress, and Expression of Aortopathy"
}

Michael D. Hope, Monica Sigovan and Petter Dyverfeldt

Linköping University Post Print

Tweet

N.B.: When citing this work, cite the original article.

Original Publication:

Michael D. Hope, Monica Sigovan and Petter Dyverfeldt, Letter by Hope et al Regarding Article, "Bicuspid Aortic Cusp Fusion Morphology Alters Aortic Three-Dimensional Outflow Patterns, Wall Shear Stress, and Expression of Aortopathy", 2014, Circulation, (130), 19, E170E170.

http://dx.doi.org/10.1161/CIRCULATIONAHA.114.008824

Copyright: American Heart Association http://www.heart.org/HEARTORG/

Postprint available at: Linköping University Electronic Press

http://urn.kb.se/resolve?urn=urn:nbn:se:liu:diva-112611 
Circulation Manuscript ID \#: 2014/008824

Title: Flow, Aortopathy and the Bicuspid Aortic Valve

Manuscript Type: Letter to the Editor

Word Count: 500 words

Journal Subject Codes: 30, 35, 58

Authors: 1. Michael D. Hope, M.D. ${ }^{1}$; 2. Monica Sigovan, $\mathrm{PhD}^{2}$; 3. Petter Dyverfeldt, $\mathrm{PhD}^{3,4}$

1. Department of Radiology and Biomedical Imaging, University of California, San Francisco.

2. University of Lyon, CREATIS Laboratory, Lyon, France

3. Division of Cardiovascular Medicine, Department of Medical and Health Sciences, Linköping University, Linköping, Sweden

4. Center for Medical Image Science and Visualization (CMIV), Linköping University, Linköping, Sweden

\section{Correspondence address:}

Michael D. Hope, M.D.

Department of Radiology and Biomedical Imaging

University of California, San Francisco

505 Parnassus Avenue, Box 0628

San Francisco, CA 94143-0628

\section{Additional Contact Information:}

Phone: (650) 714-6862

Fax: (415) 476-0616

michael.hope@ucsf.edu 


\section{Text}

We read with great interest the recent article by Dr. Mahadevia and colleagues about altered systolic flow and aortopathy with bicuspid aortic valve (BAV), and the related editorial by Drs. Uretsky and Gillam. ${ }^{1,2}$

We are pleased that the hemodynamic parameter of flow displacement performed well. It showed the clearest differences between patients with BAVs and controls, and correlated with the prearch dilation seen in patients with right-noncoronary leaflet fusion. ${ }^{1}$ Our experience with the parameter has been equally encouraging. It is easy to measure, shows excellent reproducibility, and appears to correlate well with aortic growth in initial application. ${ }^{3}$ We would like to point out, however, a technical difference between how Mahadevia et al. used flow displacement, and how it was originally intended. The parameter was correctly used to measure the distance between the "center of velocity" of forward flow and the anatomic center of the aorta. The difference is that this distance should then be normalized by the lumen diameter. This minimizes the influence of aortic geometry (note that Mahadevia et al. report elevated flow displacement with dilated aortas versus healthy volunteers; given the similar diameters of the patients with BAV and sized-matched controls, however, this influence was effectively mitigated), and maximizes the impact of valve morphology on flow. We believe this gives flow displacement the greatest likelihood of predicting disease progression caused by valve-related alteration of systolic flow.

As Uretsky and Gillam note, one problematic aspect of the work of Mahadevia et al. is that only patients with dilated aortas are included. On the one hand, this makes sense: the goal was to correlate leaflet fusions with the different patterns of aortopathy, so the focus was on older patients who had developed aortic dilation. However, from the larger perspective of the 
clinical applicability of MR flow imaging, patients without aortic dilation or valve disease are uniquely interesting. They are the most likely to fall off the radar of conventional surveillance imaging. Yet as Michelena et al. report, patients who fit this profile - young patients without significant aortic or aortic valve disease - experience substantial morbidity. ${ }^{4}$ The value of MR flow imaging may be to better risk stratify such patients through the early identification of abnormal flow that would otherwise go undetected by conventional imaging.

Not all patients with BAV have abnormal systolic flow, as Uretsky and Gillam discuss. Instead, a range of leaflet abnormalities restrict normal systolic opening to varying degrees. ${ }^{5}$ The more restricted the leaflet motion, the greater the deflection of flow from the vessel midline. Furthermore, as small initial studies from Della Corte et al. and our group suggest, the greater the flow deflection (i.e., the greater the flow displacement), the faster the ascending aorta grows., ${ }^{3,5}$ An important similarity between these initial studies is the focus on young patients with minimal aortic and aortic valve disease. This cohort should feature prominently in the larger, longitudinal studies that Uretsky and Gillam allude to for more convincing assessment of the relationship between flow abnormalities and disease progression with BAV.

Disclosures: None.

\section{References:}

1. Mahadevia R, Barker AJ, Schnell S, Entezari P, Kansal P, Fedak PW, Malaisrie SC, McCarthy P, Collins J, Carr J, Markl M. Bicuspid Aortic Cusp Fusion Morphology Alters Aortic 3D Outflow Patterns, Wall Shear Stress and Expression of Aortopathy. Circulation. 2014;129:673-82.

2. Uretsky S, Gillam LD. "Nature vs. Nurture" in Bicuspid Aortic Valve Aortopathy: More Evidence that Altered Hemodynamics May Play a Role. Circulation. 2014;129:622-4. 
3. Hope M, Sigovan M, Wrenn J, Saloner D, Dyverfeldt P. MRI Hemodynamic Markers of Progressive Bicuspid Aortic Valve-Related Aortic Disease. J. Magn. Reson. Imaging. 2013;Epub doi: 10.1002/jmri.24362

4. Michelena HI, Desjardins VA, Avierinos JF, Russo A, Nkomo VT, Sundt TM, Pellikka PA, Tajik AJ, Enriquez-Sarano M. Natural history of asymptomatic patients with normally functioning or minimally dysfunctional bicuspid aortic valve in the community. Circulation. 2008;117:2776-2784.

5. Della Corte A, Bancone C, Conti CA, Votta E, Redaelli A, Del Viscovo L, Cotrufo M. Restricted cusp motion in right-left type of bicuspid aortic valves: A new risk marker for aortopathy. J Thorac Cardiovasc Surg. 2012;144:360-369. 